\title{
Folklore ja muistaminen vernakulaarina toimintana
}

\author{
Professoriluento Turun yliopistossa 24.05.2021
}

\author{
Anne Heimo
}

$\mathrm{F}$ olkloristiikka on yksi kansallisista tieteistä, joiden syntyä ovat siivittäneet 1800-luvun lopun kansallisromanttiset pyrkimykset ja niin kutsuttu suomalaiskansallinen projekti. (Ks. esim. Anttonen 2005; Anttonen 2016.) Siitä huolimatta, että maailman vanhin folkloristiikan oppituoli löytyy Suomesta ${ }^{1}$, on tieteenala silti monelle melko tuntematon. Tämä näkyy hyvin yleisissä mielikuvissa folkloresta ja folkloristiikan tutkimuskohteista. Viime syksynä Turun yliopistossa opintonsa aloittaneet opiskelijat ihmettelivät Kulttuurien

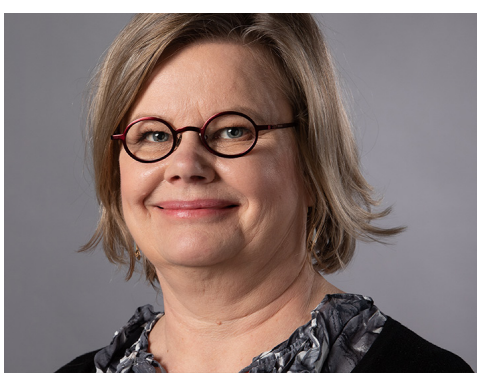

Professori Anne Heimo, TY tutkimuksen tutkinto-ohjelman perusopintoihin kuuluvan Etnologia, folkloristiikka ja uskontotiede tieteenaloina -luentokurssin oppimispäiväkirjoissaan folkloristiikan monipuolisuutta, sitä, että folkloristiikka ei olekaan vain Kalevalaa, vanhojen ihmisten haastattelemista tai meemejä.

Puhuttaessa kansanrunoudesta ja sen esittäjistä moni ajattelee ensimmäisenä Elias Lönnrotia ja hänen runonkeruumatkoilla Vienan Karjalassa kohtaamiaan iäkkäitä valkopartaisia miehiä, joku ehkä myös Larin Paraskea. Käsitys kansanrunoudesta pääosin iäkkäiden ja miesten hallitsemana perinteenä ei kuitenkaan pidä paikkansa (ks. esim. Apo, Nenola ja StarkArola (toim.) 1998; Nenola ja Timonen (toim.) 2001; Vakimo 2004), vaan kansanrunous on kuulunut silloin, kuten nykyäänkin, kaikille: nuorille ja vanhoille, lapsille ja aikuisille, naisille ja miehille. Kaikki eivät välttämättä ole hallinneet tai esittäneet kansanrunouden kaikkia eri lajeja, mutta kaikille se on ollut tuttua ja osa jokapäiväistä elämää. Sitä se on myös nykyään meille kaikille, vaikka kaikki eivät sitä ehkä osaakaan kansanrunoudeksi, eli folkloreksi, tunnistaa tai nimittää. dosenttina Kaarle Krohn nimitettiin vuonna 1908 alan ensimmäiseksi professoriksi. Turun yliopistossa folkloristiikan oppituoli on ollut vuodesta 1963 asti, jolloin Lauri Honko nimitettiin vertailevan kansanrunoudentutkimuksen professoriksi. Alun perin henkilökohtainen ja ylimääräinen professuuri muuttui vuonna 1971 pysyväksi folkloristiikan ja uskontotieteen professuuriksi. Folkloristiikka ja uskontotiede muuttuivat itsenäisiksi oppiaineiksi vuonna 1995. Oppiaineen ensimmäiseksi professoriksi nimitettiin Annikki Kaivola-Bregenhøj vuonna 1993, ensin folkloristiikan apulaisprofessoriksi ja vuonna 1995 (-2004) professoriksi. Vuonna 2006 hänen seuraajakseen nimitettiin Pekka Hakamies, joka toimi tehtävässä vuoteen 2018. 


\section{Folkloren monet käyttöyhteydet}

Folklorella tarkoitetaan henkistä kansankulttuuria - nykyään puhutaan usein aineettomasta kulttuuriperinnöstä. Usein henkisellä kansakulttuurilla tarkoitetaan nimenomaan suullista perinnettä, vaikka kaikki folklore ei suinkaan ole suullista. (Heimo 2018.) Tieteen termipankin määritelmän mukaan folklore voidaan suppeimmillaan käsittää kirjoittamattomaksi kirjallisuudeksi, kansan sanataiteeksi, johon kuuluu kansanrunouden eri muodot eeppisistä runoista kansankertomuksiin. Laveimmillaan folklorella tarkoitetaan kaikkea kansanomaista kulttuuria, leikkejä, kansanlauluja ja -tansseja, käsitöitä tai vaikkapa omaleimaista paikallista rakennuskulttuuria. (Tieteen termipankki 8.5.2021: Folkloristiikka: folklore. Tarkka osoite: https://tieteentermipankki.fi/wiki/Folkloristiikka:folklore.)

Folklorea tuotetaan lukuisiin tarkoituksiin. Folklorella osoitetaan yhteisöllisyyttä, ilmennetään yksilöllisyyttä, erottaudutaan muista, luodaan stereotypioita, vahvistetaan ennakkoluuloja, lievennetään jännitteitä ja haastetaan valtaapitäviä. Folklorella selitetään, opetetaan, viihdytetään, houkutellaan, pelotellaan, varoitetaan ja otetaan kantaa asioiden puolesta ja vastaan. Folklorella ilmaistaan tunteita, iloitaan, surraan, lohdutetaan, pilkataan ja ivataan. Folklorea käytetään ajanvietteeksi, velvollisuuksien täyttämiseksi ja merkityksellistämään itselle tärkeitä asioita. Folklore on luovaa itseilmaisua, joka sekä toistaa että varioi vanhaa.

Perinnettä käytetään usein folkloren synonyymina, vaikka perinteessä kyse on arvottamisesta. Perinne on folklorea, jota pidetään toistamisen ja säilyttämisen arvoisena. (Anttonen 2009, 2.)

\section{Kansasta vernakulaariin}

Viime vuosikymmeninä internetistä, erityisesti sosiaalisesta mediasta, on muodostunut korvaamattoman tärkeä kanava tuottaa sekä välittää folklorea. Muutos on vaatinut monia folklorelle ominaisiksi katsottujen piirteiden tarkistamista. Digitaalisen teknologian kehittyminen on mahdollistanut yhä uusia väyliä omaehtoiselle ilmaisukulttuureille ja haastanut esimerkiksi aiempia käsityksiä folkloren vastakkaisuudesta suhteessa massamediaan, populaarikulttuuriin sekä kaupallisiin toimijoihin. (Ks. esim. Heimo 2011; Heimo 2014a; Koski 2011; Heimo ja Koski 2014.)

Nykyään folklorea onkin hedelmällisempää tarkastella vernakulaarin käsitteen avulla kuin kansanomaisen tai muiden kansa-alkuisten määritelmien kautta. (Ks. esim. Howard 2008; Noyes 2012, 15-16, 19; Goldstein 2014; Fingerroos, Hämäläinen ja Savolainen 2020.) Vernakulaarilla voidaan yhä tarkoittaa kansanomaista tai kansankielistä, mutta se ei kansa-alkuisten määritelmien tapaan perustu käsityksiin kaupunkilaiseliitin ja maalaisrahvaan, koulutettujen ja oppimattomien tai valtakulttuurin ja paikalliskulttuurin välisiin eroihin. (Koski ja Turtiainen 2020, 85.)

Vernakulaarilla tarkoitetaan omaehtoista, spontaania tai arkista kulttuuria, joka ammentaa kaikista tarjolla olevista lähteistä riippumatta siitä, mistä ne ovat alun perin lähtöisin. Vernakulaari mielletään edelleen usein vastakulttuuriksi tai alisteiseksi valtakulttuurille, mutta nykyään valta- ja vastakulttuurien väliset rajat ovat siinä määrin monimutkaistuneet ja hälvenneet, että institutionaalisten ja vernakulaarien toimijoiden suhdetta voi pikemmin 
kutsua dialogiseksi ja hybridiseksi kuin vastakkaiseksi. (Koski ja Turtiainen 2020, 85; Savolainen, Lukin ja Heimo 2020, 61-62.)

Nykyään, kun jokainen voi hyödyntää, jäljitellä ja varioida entistä helpommin kaupallisia ja kansainvälisiä sisältöjä, kuten populaarikulttuurin kuvastoja, kuluttajista on tullut samalla tuottajia. Vastaavasti nykyään kaupalliset ja institutionaaliset toimijat omaksuvat ja ottavat käyttöönsä vernakulaareja ilmaisumuotoja houkutellakseen uusia asiakkaita ja miellyttääkseen nykyisiä. (Koski ja Turtiainen 2020, 88-90.) Kukapa olisi vuosikymmen sitten uskonut, että tänä päivänä Verohallinto neuvoo asiakkaitaan meemeillä, Suomen poliisi julkaisee videoita poliisikoirien kuulumisista tai kuka tahansa voi päästä rupattelemaan presidentin kanssa sosiaalisen median välityksellä.

Muutos näkyy myös siinä, että nykyään melkeinpä kuka tahansa voi saada omalle asialleen kannatusta ilman, että hän olisi kyseisen aihealueen asiantuntija tai hänen väitteensä olisivat kestävällä pohjalla. Pahimmillaan tutkimustietoon perustumattomat väitteet voivat olla vahingollisia, kuten jos esimerkiksi niiden avulla saadaan ihmisiä kieltäytymään tarpeellisista rokotuksista, noudattamaan epäterveellisiä ruokavaliota, lietsotaan ennakkoluuloja tai kylvetään epäluuloa. Ihmisiä pyritään aktiivisesti valistamaan näistä pseudo- tai näennäistieteellisiksi usein nimitetyistä näkemyksistä ja niiden levittäjistä, mutta valistus ei useinkaan tuota toivottua tulosta, vaan saattaa peräti vahvistaa uskoa näihin.

Tarkastelemalla näitä ilmiöitä vernakulaarisena toimintana voidaan lisätä ymmärrystä ilmiöiden luonteesta, niiden taustalla olevista käsityksistä sekä siitä, mihin näiden vetovoimaisuus perustuu. (Haapoja-Mäkelä ja Lindfors 2020, 1-2.) Vernakulaariksi auktoriteetiksi voidaan kutsua itseoppinutta henkilöä, joka esimerkiksi ohjeistaa terveyteen liittyvissä asioissa ilman terveysalan koulutusta. Se, onko tämä toiminta haitallista vai ei, riippuu henkilön antamista neuvoista. Vernakulaari auktoriteetti voi olla myös henkilö, joka saavuttaa tietyn ryhmän keskuudessa johtavan aseman esittämällä vakuuttavia argumentteja asiansa puolesta. Tyypillistä tälle toiminnalle on yhtäältä akateemisten ja yhteiskunnallisten asiantuntijoiden tuottaman tiedon väheksyminen ja kiistäminen, mutta toisaalta näiden samojen tahojen toimintatapojen hyödyntäminen. Samoja keinoja käyttävät populistipoliitikot, jotka asemastaan huolimatta puheissaan identifioituvat osaksi "kansaa". (Koski ja Turtiainen, 9311001; ks. myös Johansson, Jantunen, Heimo, Ahonen ja Laippala 2018.)

Samalla on hyvä pitää mielessä, että näitä samoja vernakulaareja toimintamalleja voidaan käyttää yhtä lailla meille kaikille tärkeiden asioiden edistämiseen, kuten kampanjoimalla inmisoikeuksien ja tasa-arvon lisäämiseksi, ilmastokriisin estämiseksi tai nykyisten ja menneiden vääryyksien esille nostamiseen ja näiden muistamiseen.

\section{Muistamisen prosessit ja kulttuurinen muisti}

Yhteiskunnan muuttuessa muistamisen kohteet ja tavat muuttuvat. Esimerkiksi Suomen sisällissodan jälkeen sodan eri osapuolet muistelivat sotaa kumpikin tahoillaan muistelmissa, historiikeissa ja omissa tapahtumissaan, vaikka sodan julkinen muistaminen kuuluikin voittajille vuosikymmenten ajan. (Ks. esim. Heimo 2010; McKeough 2017; Peltonen 1996; Peltonen 2003.) Nyt sisällissodan muistaminen on siirtynyt verkkoon, erityisesti Facebookiin, jonka ryhmät ovat osoittautuneet erityisen otolliseksi muistelemiselle. Sosiaalisen median jatkuvassa uutisvirrassa on kuitenkin hyvin vaikea herättää huomioita pelkällä tekstillä, joten 
tekstin seuraksi on lisättävä visuaalinen komponentti, kuten kuva tai video. Nykyään tyypillinen sisällissodan muistojulkaisu koostuu kuvasta esimerkiksi sodassa mukana olleesta sukulaisesta, tämän hautapaikasta tai hänelle kuuluneesta esineestä sekä näihin liittyvistä perhekertomuksista. (Ks. esim. Heimo 2014b; Savolainen, Lukin ja Heimo 2020, 65-70.)

Verkossa muistelu on ajasta ja paikasta riippumatonta. Verkko on muuttanut myös käsityksiämme yksityisyydestä ja julkisuudesta. Tämä näkyy erityisen hyvin esimerkiksi Facebook-ryhmissä, joihin kuuluu eri puolilla maailmaa asuvia ihmisiä, joilla on sukujuuret Suomessa. Ryhmissä etsitään ja vaihdetaan tietoja sukulaisista, käännetään yhdessä vierailla kielillä kirjoitettuja kirjeitä, julkaistaan henkilökohtaisia tai arkistoista löydettyjä asiakirjoja, kerrotaan omia perhemuistoja ja muistellaan yhdessä samankaltaisia kokemuksia omaavien kanssa. Omasta elämästä kerrotaan nykyään auliisti muiden kanssa, vaikka heitä ei entuudestaan tuntisikaan. Pääasia on tunne yhteenkuuluvuudesta. (Ks. esim. Heimo 2017; Heimo ja Salmi-Niklander 2019, 596-599.)

Kulttuurisella muistilla viitataan niihin tapoihin, joilla yksilöt ja yhteisöt nykyhetkessä rakentavat ja pitävät yllä suhdettaan menneisyyteen pitäen samalla mielessä tulevaisuuden tarpeet. Kulttuurisella muistilla ja folklorella on monia yhtymäkohtia, joten ei ole yllättävää, että monia folkloristeja kiinnostavat muistamisen prosessit. Muistoja ei voi välittää tai ymmärtää ilman, että niistä muokataan kertomuksia. Nämäkin kertomukset ovat yhteisöllisesti muovattuja ja niitä tuotetaan jatkuvassa vuorovaikutuksessa median, populaarikulttuurin sekä eri instituutioiden kanssa. Ajan kuluessa näistä kertomuksista voi syntyä yhteiskunnassa laajasti tunnettuja kulttuurisia kertomuksia, joilla käsitellään yhteisiä kokemuksia ja, joita tarpeen tullen välitetään tuleville sukupolville.

\section{Kirjallisuus}

Anttonen, Pertti. 2005. Tradition through Modernity: Postmodernism and the Nation-State in Folklore Scholarship Helsinki: Finnish Literature Society. https://doi.org/10.21435/sff.15.

Anttonen, Pertti. 2009. "Kulttuurin, perinteen ja perinnön kysymyksiä." Elore 16(1), 1-8. https://doi.org/10.30666/elore.78777.

Anttonen, Pertti. 2016. "Professuuriesitelmä: Pertti Anttonen: Perinteentutkimuksen projekti." Elore 23(1). https://doi.org/10.30666/elore.79243.

Apo, Satu, Aili Nenola ja Laura Stark-Arola (toim.).1998. Gender and Folklore. Perspectives on Finnish and Karelian Culture. Studia Fennica Folkloristica 4. Helsinki: Finnish Literature Society.

Fingerroos, Outi, Niina Hämäläinen ja Ulla Savolainen. 2020. "Mikä vernakulaari?"Elore 27(1), 4-14. https://doi.org/10.30666/elore.95523.

Goldstein, Diane E. 2015. "Vernacular Turns: Narrative, Local Knowledge, and Changed Context of Folklore." Journal of American Folklore 128 (508): 125-145. https://www.jstor. org/stable/10.5406/jamerfolk.128.508.0125?seq=1.

Haapoja-Mäkelä, Heidi ja Antti Lindfors. 2020. "Polarisaatiota vastaan folkloristin asein." Elore 27(2), 1-3. https://doi.org/10.30666/elore.101282. 
Heimo, Anne. 2010. Kapina Sammatissa. Vuoden 1918 paikalliset tulkinnat osana historian yhteiskunnallisen rakentamisen prosessia. Helsinki: Suomalaisen Kirjallisuuden Seura.

Heimo, Anne. 2011. "Saatteeksi: Folkloristit ja internet - Aave koneessa?" Elore 18(1), 1-7. https://doi.org/10.30666/elore.78916.

Heimo, Anne. 2013. "Meemi tulee. Folkloristi, oletko valmis?" Elore 20(2), 1-13. https://doi. org/10.30666/elore.79087.

Heimo, Anne. 2014a. "Esitelmä: Omaehtoista historiantuottamista." Elore 21(2). https://doi. org/10.30666/elore.79158.

Heimo, Anne. 2014b."The 1918 Finnish Civil War Revisited: The Digital Aftermath." Folklore 57, 141-168. https://doi:10.7592/FEJF2014.57.heimo.

Heimo, Anne. 2017."The Italian Hall tragedy, 1913: A hundred years of remediated memories." Teoksessa The Twentieth Century in European Memory: Transcultural mediation and reception, toimittaneet Barbara Törnqvist-Plewa ja Tea Sindbæk Andersen, 240-267. Leiden: Brill. doi:10.1163/9789004352353_012.

Heimo, Anne. 2018. "Mitä on suullinen perinne?" Suomalaisen Kirjallisuuden Seuran blogi Vähäisiä lisiä 2.2.2018. http://neba.finlit.fi/blogi/mita-on-suullinen-perinne/.

Heimo, Anne ja Kaarina Koski. 2014. "Internet Memes as Statements and Entertainment." FF Network 44, 4-12. https://www.folklorefellows.fi/wp-content/uploads/FFNetwork 44. pdf.

Heimo, Anne ja Kirsti Salmi-Niklander. 2019."Everyday reading cultures of Finnish immigrant communities." Participations: Journal of Audience \& Reception Studies, 582-604. https:// www.participations.org/Volume\%2016/lssue\%201/27.pdf.

Howard, Robert Glenn. 2008. "The Vernacular Web of Participatory Media." Critical Studies in Media Communication 25(5): 490-513.

Koski, Kaarina. 2011. "Mediakulttuurin murros, YouTube ja folklore." Elore 18(1), 14-27. https://journal.fi/elore/article/view/78918/39820.

Koski, Kaarina ja Riikka Turtiainen. 2020. "Vernakulaari verkossa: vertaisuuden ilmaisemisen digitaaliset ulottuvuudet." Elore 27(1), 85-107. https://doi.org/10.30666/elore.88834.

Johansson, Marjut, Jarmo H. Jantunen, Anne Heimo, Mirka Ahonen ja Veronika Laippala. 2018. "Verkkokeskustelujen kansa." Sananjalka. Suomen Kielen Seuran Vuosikirja 60, 961-17. Turku: Suomen Kielen Seura.

McKeough, Andreas. 2017. Kirjoittaen kerrottu sota: tutkimus vuoden 1918 sodan kerronnallisesta käsittelystä omaelämäkerrallisissa teksteissä Helsinki: Työväen historian ja perinteen tutkimuksen seura.

Nenola, Ailija SenniTimonen (toim.). 1991. Louhen sanat. Helsinki:Suomalaisen Kirjallisuuden Seura.

Noyes, Dorothy. 2012. "The Social Base of Folklore." Teoksessa A Companion to Folklore, toimittaneet Regina Bendix ja Galit Hasan-Rokem, 13-30. Chichester: John Wiley \& Sons.

Peltonen, Ulla-Maija. 1996. Punakapinan muistot: tutkimus työväen muistelukerronnan muotoutumisesta vuoden 1918 jälkeen Helsinki: Suomalaisen Kirjallisuuden Seura.

Peltonen, Ulla-Maija. 2003. Muistin paikat: vuoden 1918 sisällissodan muistamisesta ja unohtamisesta Helsinki: Suomalaisen Kirjallisuuden Seura. 
Savolainen, Ulla, Karina Lukin ja Anne Heimo. 2020. "Omaehtoisen muistamisen materiaalisuus ja monimediaisuus: muistitietotutkimus ja uusmaterialismi." Elore 27(1), 60-84. http://dx.doi.org/10.30666/elore.89039.

Tieteen termipankki 2021. https://tieteentermipankki.fi/.

Vakimo, Sinikka. 2004. "Gender in Finnish folkloristics - outlines of broadening fields." FF Network 27, 7-18. https://www.folklorefellows.fi/wp-content/uploads/FFN_27.pdf.

Anne Heimo on folkloristiikan professori Turun yliopiston historian, kulttuurin ja taiteiden tutkimuksen laitoksella.

Tallenne luennosta saatavilla osoitteesta https://www.utu.fi/fi/yliopisto/akateemiset-juhlat/ professoriluennot/toukokuu-2021/anne-heimo. 